\title{
Variations of nutrient contents between healthy and insect-damaged Hippophae rhamnoides ssp. sinensis
}

\author{
Lili Xu ${ }^{1}$, Rong Wang ${ }^{1}$, Linfeng Yu ${ }^{1}$, Tao Wang ${ }^{2}$, Shixiang Zong ${ }^{1}$ *, Pengfei Lu ${ }^{1}$ \\ ${ }^{1}$ The Key Laboratory of Beijing for Control to Forest Pest, Beijing Forestry University, Beijing, 100083, P. R. China \\ ${ }^{2}$ Mentougou Forestry Station, Beijing, 102300, China
}

\section{Email address:}

zongsx@126.com (Shixiang Zong)

\section{To cite this article:}

Lili Xu, Rong Wang, Linfeng Yu, Tao Wang, Shixiang Zong, Pengfei Lu. Variations of Nutrient Contents between Healthy and Insect-Damaged Hippophae Rhamnoides Ssp. Sinensis. American Journal of Agriculture and Forestry. Vol. 2, No. 4, 2014 , pp. $192-198$. doi: 10.11648/j.ajaf.20140204.22

\begin{abstract}
The moisture contents, nutrients and mineral elements of the different sections of healthy and insect-damaged Hippophae rhamnoides ssp. sinensis were analysed to evaluate changes in the nutrient content of plants after damage by Holcocerus hippophaecolus. In affected plants, no significant differences in protein or moisture contents were observed in all three sections. Ash contents decreased significantly in the top and lower sections, potassium and zinc contents decreased significantly in all three sections. The total contents of amino acids significantly increased in the middle and lower sections. Proline and cysteine amounts increased significantly in all three sections. Damage-induced variation in the contents of nutrient substances in the different sections had a strong impact on the metabolism and growth of plants. The present results reveal the mechanism underlying the death or injury of $H$. rhamnoides ssp. sinensis caused by H. hippophaecolus.
\end{abstract}

Keywords: Causes of Death, Holcocerus Hippophaecolus, Mineral Element, Nutrient Substances

\section{Introduction}

Hippophae rhamnoides ssp. sinensis is a type of deciduous tree or shrub that belongs to the Hippophae species (Elaeagnaceae). It is an excellent pioneer tree species for water and soil conservation, sand and storm treatment and forestation in the arid and semi-arid regions of Western China [1]. It has high economic value because its berries have medical and health-promoting properties, and can be processed into jams, juices, yellow pigments, and seed oils. Its branches and leaves are also good feed shrub [2,3].

Holcocerus hippophaecolus belongs to the Holcocerus species (Cossidae, Lepidoptera), which is mainly distributed in large areas in the Inner Mongolia Autonomous Region, Ningxia Hui Autonomous Region, Liaoning, Hebei, Shanxi, and Shaanxi provinces in China. Although its host plant is mainly the sea buckthorn, it can also attack Salix cheilophila, Ulmus, Elaeagnus angustifolia L., and Siberian Apricot. Its larvae bore into the stems of the plant, often rendering the stem hollow, resulting in the death of the infected tree $(4,5,6,7)$. In recent years, $H$. hippophaecolus has caused the death of millions of sea buckthorn stands, strongly impacting the ecological construction and economic development.
Recent research on the sea buckthorn has focused on the development of artificial cultivation and breeding [8], the antioxidant potential and total phenolic contents of sea buckthorn pomace [9], and product development based on this plant [10]. Most studies addressing the nutrient content of this plant have focused on its berries, investigating changes in sugar, organic acid, flavonol and carotenoid composition during the ripening of the berries of three sea buckthorn cultivars [11], the quality components of sea buckthorn varieties [12], and the effects of different origins and harvesting time on vitamin $\mathrm{C}$, tocopherols, and tocotrienols in sea buckthorn berries [13]. However, the differences in nutrient substances between healthy and damaged $H$. rhamnoides ssp. sinensis have not been reported.

In the present study, a planted $H$. rhamnoides ssp. sinensis forest was used to investigate changes in the amino acid, protein, mineral element (phosphorous, potassium, and magnesium), and moisture contents of different sections (top, middle, and lower sections) sampled from healthy and damaged $H$. rhamnoides ssp. sinensis plants. The aim of the study was to provide a theoretical understanding of the mechanism that leads to death after damage caused by $H$. hippophaecolus. 


\section{Materials and Methods}

\subsection{Materials}

H. rhamnoides ssp. sinensis samples were collected from a forest planted in Hexian, Pengyang city, Ningxia, China. The H. rhamnoides ssp. sinensis trees were six years old, with an average height of $2.0 \mathrm{~m}$ and an average diameter of $4.5 \mathrm{~cm}$ at the base.

\subsection{Experimental Design}

In August 2011, three healthy and three damaged $H$. rhamnoides ssp. sinensis shrubs were selected based on the comprehensive sampling of shrubs at the same site (similar growth, height, and diameter). Within the damaged forest, $26 \%$ of the $H$. rhamnoides ssp. sinensis shrubs were affected by $H$. hippophaecolus, and the population density was 0.73 larvae per plant. The damaged shrubs were planted at a high density. $H$. hippophaecolus had damaged the roots and trunk of $H$. rhamnoides ssp. sinensis. Samples (20 g) were collected from undamaged sections of affected shrubs, with the root and trunk used as demarcation points. Therefore, samples were obtained from sites above the damaged root, between the damaged root and the damaged trunk, and below the damaged root. Similar samples were collected from healthy shrubs. The top, middle, and lower sections were used to simplify the sampling process, from the tips of the branches to the roots.

\subsection{Nutrient Analysis}

The samples were analysed at the Analysis Laboratory of Beijing Nutrition Resources Institute.

\subsubsection{Moisture Determining}

The moisture content was measured using the direct drying method [14]. The samples were weighed immediately after collecting, then put it in $105^{\circ} \mathrm{C}$ of ovens dried to a constant weight to calculate the moisture.

\subsubsection{Content of Amino Acid Determining}

The amino acid contents were determined by ion exchange chromatography [15]. $0.3 \mathrm{~g}$ of sample dry powder, add $5 \mathrm{~mL}$ of $6 \mathrm{~mol} / \mathrm{L} \mathrm{HCl}$ solution, hydrolysis for 22 hours in $110^{\circ} \mathrm{C}$ of ovens. Filtrate at low temperature steam and dry, dissolve it in $1 \mathrm{~mL}$ buffered solution which $\mathrm{pH}$ is 2.2 , reserve, $50 \mu \mathrm{L}$ of it is used to enter the machine.

\subsubsection{Content of Protein Determining}

The protein content was analysed using the Kjeldahl method [16]. Add $0.3 \mathrm{~g}$ of sample in $50 \mathrm{~mL}$ toper bottle, then add $0.20 \mathrm{~g}$ of $\mathrm{CuSO} 4,5.00 \mathrm{~g}$ of $\mathrm{K} 2 \mathrm{SO} 4,8.5 \mathrm{~mL}$ of oil of vitriol, digest on the electric stove in the fume hood until the digestive juice get slight green, to continue heating for 30 minutes again. Then put it to the protein analyzer, using $0.05 \mathrm{~mol} / \mathrm{L}$ sulphuric acid as standard titration solution.

\subsubsection{Content of Ash Determining}

The ash content was determined by combustion [17].
$5.00 \mathrm{~g}$ of sample dry powder ignition to constant weight in $550^{\circ} \mathrm{C}$ of muffle furnace, take it out until it was cooled to $200^{\circ} \mathrm{C}$, then weigh it after putting it in drying apparatus for $30 \mathrm{~min}$.

\subsubsection{Content of Zinc Determining}

The zinc content was determined by atomic absorption spectrometry [18]. 5.00g of sample dry powder ignition in $550^{\circ} \mathrm{C}$ of muffle furnace for 8 hours, after it cool to room temperature and then add mixed acid (nitric acid: perchloric acid $=3: 1$, low heat, can add some mixed acid to make it do not dry up, heat until there was no carbon granule among the leavings, dilute to $50 \mathrm{~mL}$. The zinc content was determined by flame atomizer, the wavelength is $213.8 \mathrm{~nm}$.

\subsubsection{Content of Potassium and Sodium, Calcium, Iron, Magnesium and Manganese Determining}

Potassium and sodium contents were analysed by flame emission spectrometry [19], Calcium [20], iron, magnesium and manganese [21] were analysed by atomic absorption spectrophotometry. Using $0.5 \mathrm{~g}$ of sample dry powder, add $25 \mathrm{~mL}$ of mixed acid (nitric acid: perchloric acid $=3: 1$ ), and then digest in platen heater, cool it until get 2-3 mL digestive juice, one-sixth of it dilute to $10 \mathrm{~mL}$ by lanthanum oxide for calcium determining, others dilute to $10 \mathrm{~mL}$ by distilled water. Then determine potassium and sodium contents by flame photometer, the wavelength is $766.5 \mathrm{~nm}$ for potassium and $589 \mathrm{~nm}$ for sodium. Calcium, iron, magnesium and manganese contents were determined by atomic absorption spectrophotometer, the wavelength is $422.7 \mathrm{~nm}$ for calcium, $248.3 \mathrm{~nm}$ for iron, $285.2 \mathrm{~nm}$ for magnesium and 279.5 for manganese.

\subsubsection{Content of Copper Determining}

Copper was determined using the flame atom absorption method [22]. Weigh $2 \mathrm{~g}$ of sample dry powder, add $5 \mathrm{~mL}$ of nitric acid, standing for 0.5 hour, after charing by heat, ignition in $500^{\circ} \mathrm{C}$ of muffle furnace for 0.5 hour, after it cool to room temperature then dissolve it nitric acid, dilute to $10 \mathrm{~mL}$, then determined it by flame atomizer, the wavelength is $324.8 \mathrm{~nm}$.

\subsection{Statistical Analysis}

The experimental data were analyzed using Microsoft Excel 2010 (Microsoft). Graph production and tests of statistically significant differences were performed using Prism 5, t-test (GraphPad Software, Inc., La Jolla, CA, USA).

\section{Results}

\subsection{Differences in Moisture Content in the Same Section between Healthy and Damaged H. Rhamnoides ssp. Sinensis}

The differences in the moisture contents of the three sections between healthy and insect-damaged $H$. rhamnoides ssp. sinensis are shown in Figure 1. Moisture contents of insect-damaged $H$. rhamnoides ssp. sinensis 
were lower than those of healthy $H$. rhamnoides ssp. sinensis plants in all three sections, without significant differences between the sections. The middle section showed the greatest decline $(9.55 \%)$ and the top section showed the least decline $(2.87 \%)$.

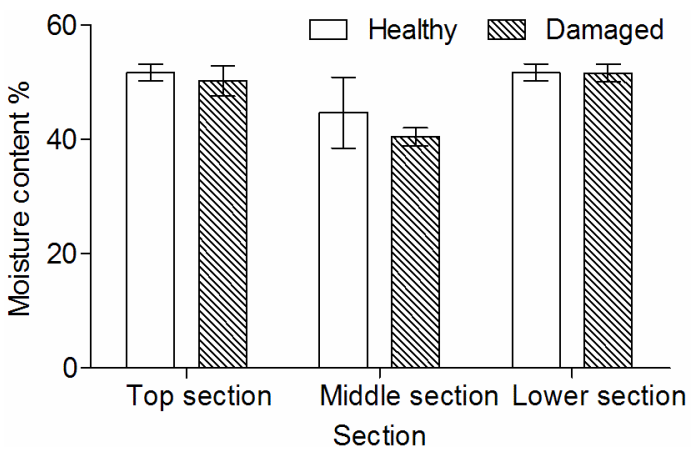

Figure 1. Moisture contents of healthy and damaged H. rhamnoides ssp. Sinensis

\subsection{Differences in Ash Content in the Same Section between Healthy and Damaged H. Rhamnoides ssp. Sinensis}

The differences in the ash contents of the three sections between healthy and insect-damaged $H$. rhamnoides ssp. sinensis are shown in Figure 2. Ash contents were lower in insect-damaged than in healthy $H$. rhamnoides ssp. sinensis in all three sections. The top section $(\mathrm{t}=4.129, \mathrm{P}<0.01)$ and lower section $(\mathrm{t}=2.987, \mathrm{P}<0.05)$ showed a significant decrease $(50.19 \%$ and $36.43 \%$, respectively). No significant decrease was observed in the middle section.

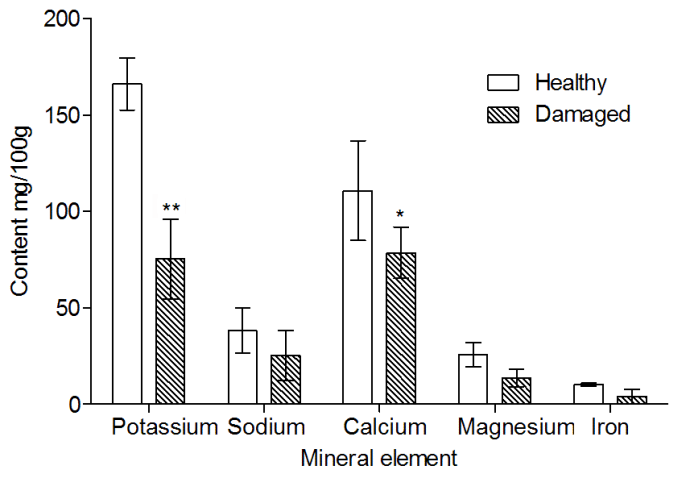

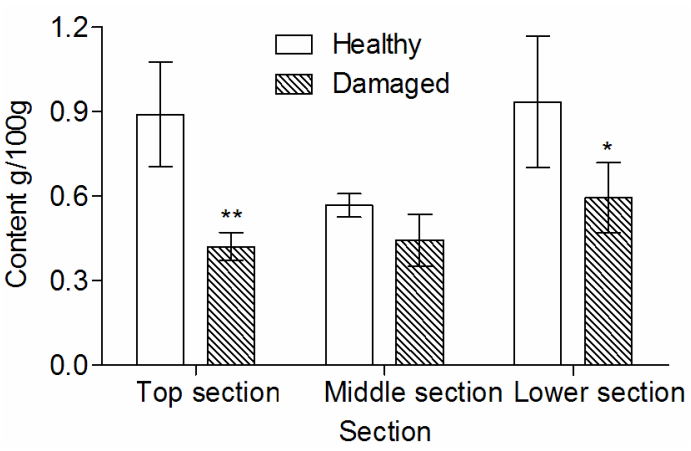

Figure 2. Ash contents of healthy and damaged H. rhamnoides ssp. Sinensis

Note: Data are expressed as the mean \pm standard deviation $(\mathrm{n}=3)$, “**" Indicates highly significant differences compared with controls $(\mathrm{p}<0.01)$, “*” Indicates significant differences compared with controls $(\mathrm{p}<0.05)$.

\subsection{Differences in Mineral Element Content In the Same Section between Healthy and Damaged $H$. Rhamnoides ssp. Sinensis}

\subsubsection{Variations of Mineral Element Content in the Top Section}

The differences in the mineral element contents of the top section between healthy and insect-damaged $H$. rhamnoides ssp. sinensis are shown in Figure 3. In insect-damaged plants, the contents of all mineral elements that were tested decreased except copper, which increased in the top section compared with the contents of healthy $H$. rhamnoides ssp. sinensis. Potassium $(\mathrm{t}=8.197, \mathrm{P}<0.01)$, manganese $(\mathrm{t}=$ 4.035, $\mathrm{P}<0.01)$, zinc $(\mathrm{t}=6.675, \mathrm{P}<0.01)$ and calcium $(\mathrm{t}=$ $2.917, \mathrm{P}<0.05)$ decreased significantly by $54.62 \%, 40.35 \%$, $60.90 \%$ and $29.12 \%$, respectively. No significant variation in other mineral elements was observed.

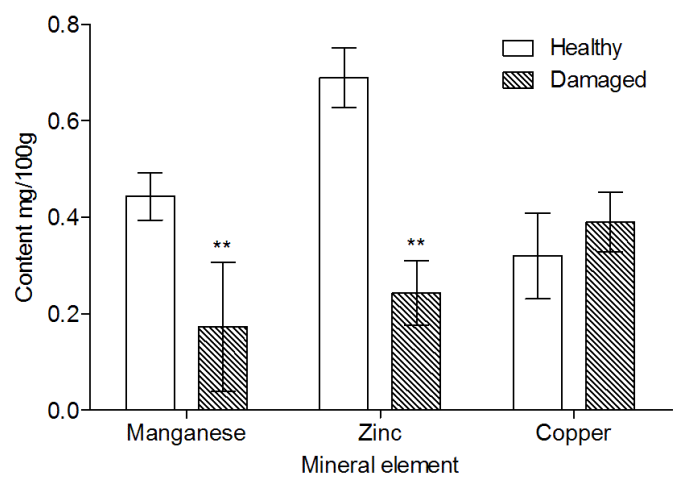

Figure 3. Types and contents of mineral elements in the top section of healthy and damaged H. rhamnoides ssp. Sinensis

\subsubsection{Variations of Mineral Element Content in the Middle Section}

Differences in the contents of mineral elements in the middle section between healthy and insect-damaged $H$. rhamnoides ssp. sinensis are shown in Figure 4. In insect-damaged plants, the contents of all the mineral elements that were tested decreased except copper and calcium (no significant increase was found), which increased in the middle section compared with the contents of healthy $H$. rhamnoides ssp. sinensis. Potassium $(\mathrm{t}=$ 5.015, $\mathrm{P}<0.01)$ and zinc $(\mathrm{t}=4.702, \mathrm{P}<0.01)$ decreased significantly by $40.32 \%$ and $62.92 \%$, respectively. No significant variation in other mineral elements was observed. 

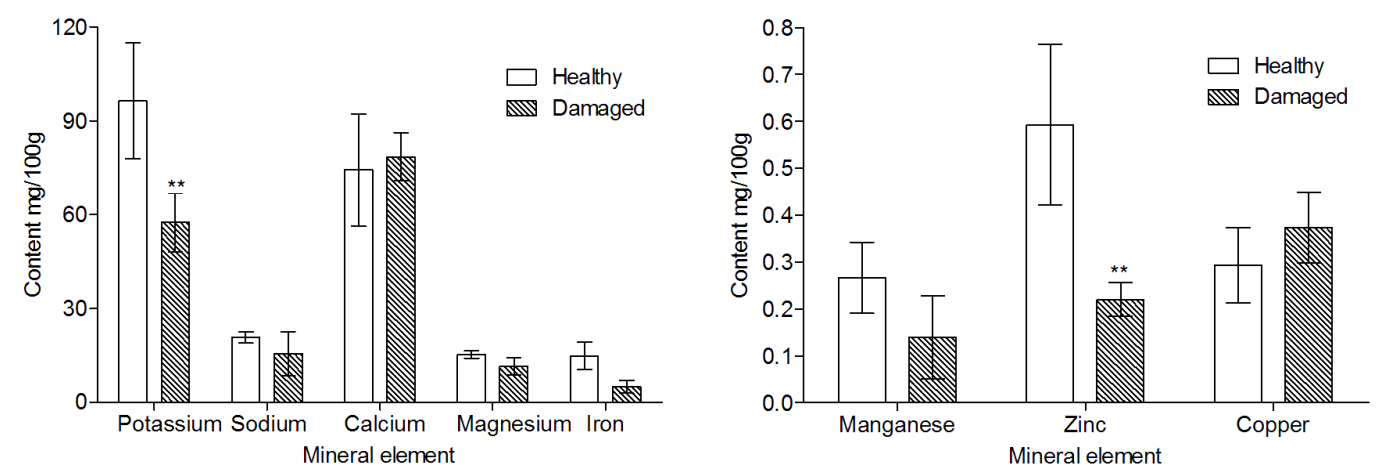

Figure 4. Types and contents of mineral elements in the middle section of healthy and damaged H. rhamnoides ssp. Sinensis

\subsubsection{Variations in the Mineral Element Content in the Lower Section}

Differences in the contents of mineral elements in the lower section between healthy and insect-damaged $H$. rhamnoides ssp. sinensis are shown in Figure 5. In insect-damaged plants, all the mineral element contents

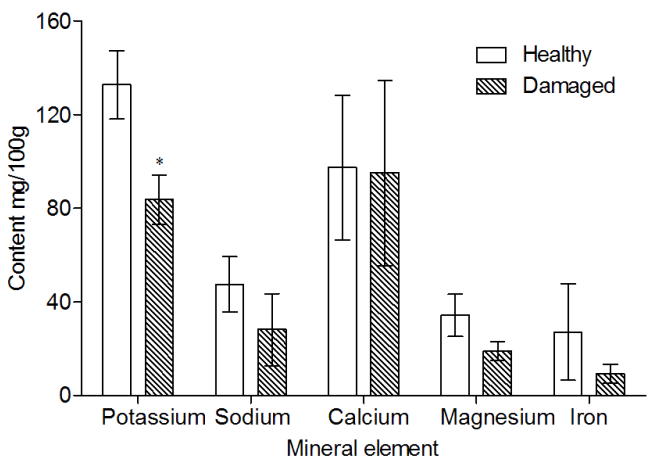

Figure 5. Types and contents of mineral elements in the lower section of healthy and damaged H. rhamnoides ssp. Sinensis

\subsection{Differences in Amino Acid Content in the Same \\ Section between Healthy and Damaged $\mathrm{H}$. Rhamnoides ssp. Sinensis}

Amino acid composition analysis identified 18 amino acids in the three sections of $H$. rhamnoides ssp. sinensis, namely Aspartate (ASP), Threonine (THR), Serine (SER), Glutamate (GLU), Glycine (GLY), Alanine (ALA), Valine (VAL), Methionine (MET), Isoleucine (ILE), Leucine (LEU), Tyrosine (TYR), Phenylalanine (PHE), Lysine (LYS), Histidine (HIS), Arginine (ARG), Proline (PRO), Tryptophan (TRP) and Cysteine (CYS).

\subsubsection{Variations in the Total Amino Acid Content}

Differences in the total amino acid content between healthy and insect-damaged $H$. rhamnoides ssp. sinensis are shown in Figure 6 . The total amino acid content was higher in insect-damaged than in healthy $H$. rhamnoides ssp. sinensis in all three sections. Total amino acids increased significantly in the middle $(\mathrm{t}=3.935, \mathrm{P}<0.01)$ and lower $(\mathrm{t}$ $=3.481, \mathrm{P}<0.05)$ sections by $27.70 \%$ and $19.97 \%$, respectively. No significant increase was observed in the top section. decreased except copper, which increased in the lower section compared with the contents of healthy $H$. rhamnoides ssp. sinensis. Potassium $(\mathrm{t}=3.100, \mathrm{P}<0.05)$ and zinc $(\mathrm{t}=3.709, \mathrm{P}<0.01)$ decreased significantly by $36.95 \%$ and $64.53 \%$, respectively. No significant variation in other mineral elements was observed.

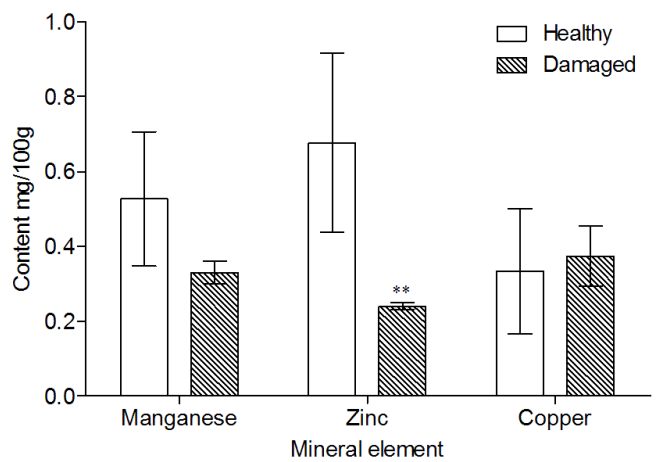

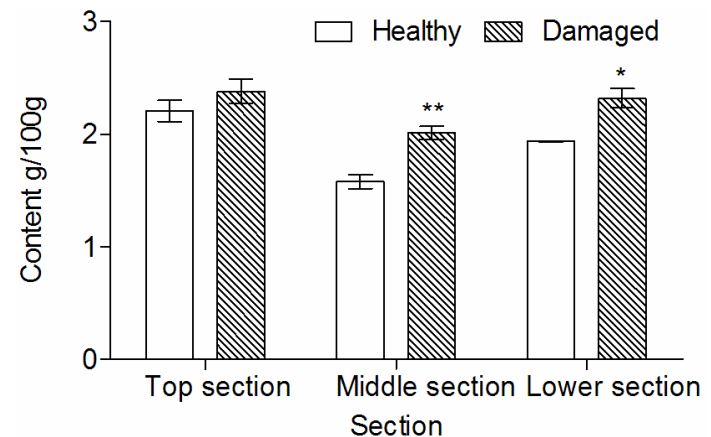

Figure 6. Total contents of amino acids in healthy and damaged $H$. rhamnoides ssp. Sinensis

\subsubsection{Variations in the Content of Amino Acids in the Top Section}

Differences in the content of amino acids in the top section between healthy and insect-damaged $H$. rhamnoides ssp. sinensis are shown in Figure 7. In insect-damaged plants, the contents of all the amino acids tested increased in the top section except ASP, SER, GLU, ALA, LEU and TYR, which decreased compared with the contents of healthy $H$. rhamnoides ssp. sinensis. $\mathrm{PRO}(\mathrm{t}=3.209, \mathrm{P}<$ $0.05)$, TRP $(\mathrm{t}=3.582, \mathrm{P}<0.05)$, LYS $(\mathrm{t}=3.806, \mathrm{P}<0.01)$ 
and CYS ( $\mathrm{t}=5.896, \mathrm{P}<0.01)$ increased significantly by $24.39 \%, 236.07 \%, 57.74 \%$ and $53.50 \%$, respectively. No significant variation in other amino acids was observed.

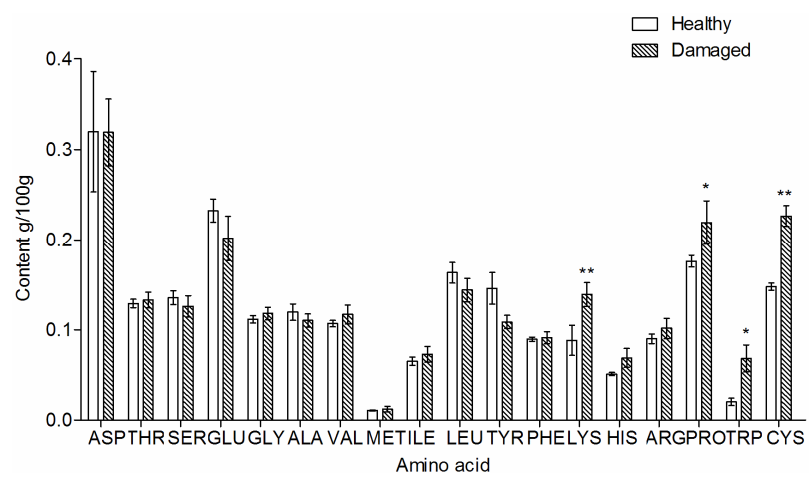

Figure 7. Types and contents of amino acids in the top section of healthy and damaged H. rhamnoides ssp. Sinensis

\subsubsection{Variations in the Content of Amino Acids in the Middle Section}

Differences in the contents of amino acids in the middle section between healthy and insect-damaged $H$. rhamnoides ssp. sinensis are shown in Figure 8. In insect-damaged plants, the contents of all amino acids in the middle section increased except TYR, which decreased compared with the contents of healthy $H$. rhamnoides ssp. sinensis. GLY $(\mathrm{t}=$ 3.218, $\mathrm{P}<0.05)$, ASP $(\mathrm{t}=3.961, \mathrm{P}<0.01)$, LYS $(\mathrm{t}=8.541, \mathrm{P}$ $<0.01)$, HIS $(\mathrm{t}=3.755, \mathrm{P}<0.01), \mathrm{PRO}(\mathrm{t}=8.334, \mathrm{P}<0.01)$, TRP $(\mathrm{t}=5.941, \mathrm{P}<0.01)$ and CYS $(\mathrm{t}=8.912, \mathrm{P}<0.01)$ increased significantly by $32.64 \%, 15.14 \%, 148.92 \%$, $101.11 \%, 55.80 \%, 300.00 \%$ and $52.17 \%$, respectively. No significant variation in other amino acids was observed.

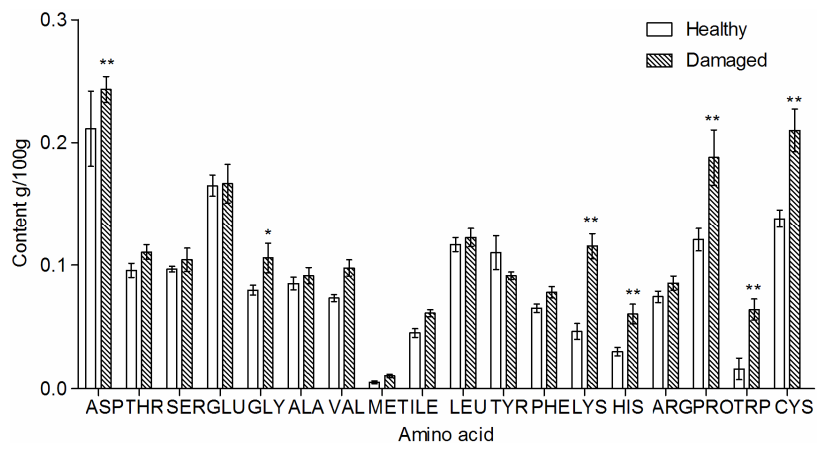

Figure 8. Types and contents of amino acids in the middle section of healthy and damaged H. rhamnoides ssp. Sinensis

\subsubsection{Variations in the Content of Amino Acids in the Lower Section}

Differences in the contents of amino acids in the lower section between healthy and insect-damaged $H$. rhamnoides ssp. sinensis are shown in Figure 9. In insect-damaged plants, the contents of all the amino acids that were tested increased in the lower section except SER, GLU and TYR, which decreased compared with the contents of healthy $H$. rhamnoides $\mathrm{ssp}$. sinensis. LYS $(\mathrm{t}=3.342, \mathrm{P}<0.05), \mathrm{PRO}(\mathrm{t}$ $=3.579, \mathrm{P}<0.05)$ and CYS $(\mathrm{t}=5.954, \mathrm{P}<0.01)$ increased significantly by $85.51 \%, 42.24 \%$ and $82.74 \%$, respectively.
No significant variation in other amino acids was observed.

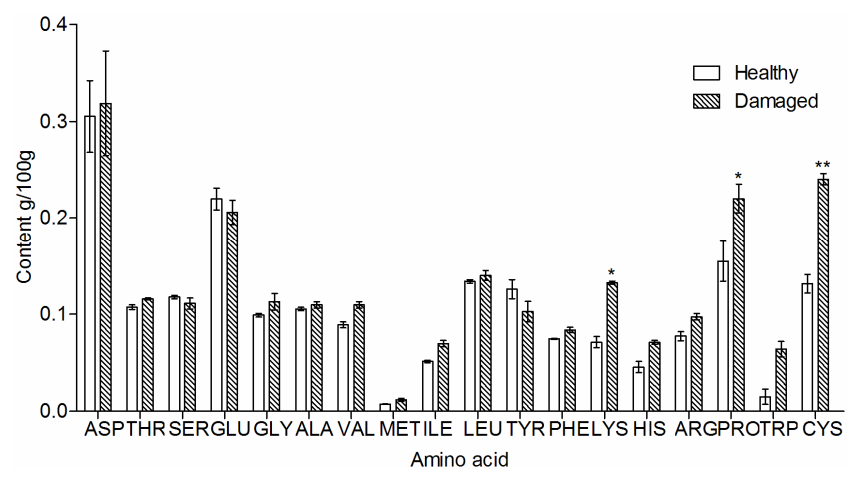

Figure 9. Types and contents of amino acids in the lower section of healthy and damaged H. rhamnoides ssp. Sinensis

\subsection{Differences in the Protein Content in the Same Section between Healthy and Damaged H. Rhamnoides ssp. Sinensis}

Differences in the protein contents of the three sections between healthy and insect-damaged $H$. rhamnoides ssp. sinensis are shown in Figure 10. In insect-damaged plants, the protein contents of $H$. rhamnoides ssp. sinensis decreased in the top and lower sections and increased in the middle section. The protein content of the top section decreased by $22.54 \%$ and that of the lower section decreased by $0.95 \%$, whereas the protein in the middle section increased by $11.38 \%$.

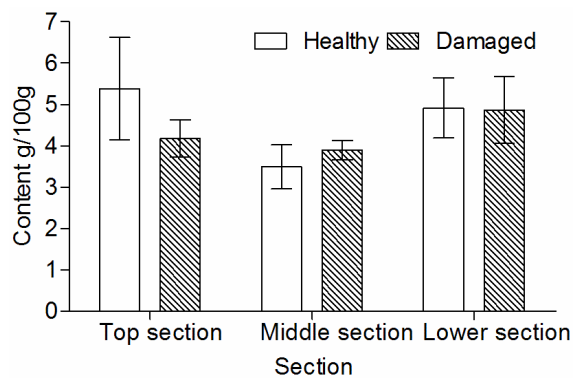

Figure 10. Protein contents of healthy and damaged H. rhamnoides ssp. Sinensis

\section{Discussion}

\subsection{Variations in the Moisture Contents of H. Rhamnoides ssp. Sinensis after Insect Damage}

In August, transpirational pull is one of the most important forces driving root water uptake in $H$. rhamnoides ssp. sinensis. Damage to the xylem in root and cadres disrupted the water-mass continuity, which affected the water-absorption ability of the plant, resulting in a decline in moisture content in all three sections. $H$. rhamnoides ssp. sinensis grew under dry conditions with a significantly lower moisture content than that of normal plants; therefore, no significant differences in moisture content were observed between the healthy and insect-damaged H. rhamnoides ssp. sinensis. 


\subsection{Variations in the Ash Contents of H. Rhamnoides ssp. Sinensis after Insect Damage}

The ash content is the sum of mineral oxides, which is directly proportional to the content of mineral elements. In insect-damaged plants, the decrease in moisture content resulted in the translocation of mineral elements, and their absorption by the xylem in root and cadres was disrupted. This reduced the rate of absorption and the capacity to translocate mineral elements, resulting in a decrease in ash contents in the three sections.

In damaged plants, the top section showed the greatest decline and the middle section showed the least decline. A greater demand for mineral elements in damaged sections than in undamaged sections is associated with the acceleration of wound concrescence. Ash content declined significantly in the top section and mineral elements could not be sufficiently translocated to the leaves in time, which inhibited photosynthesis. Ash content declined significantly in the lower section, which inhibited the growth of the roots, and the ability to absorb water, mineral elements and amino acids was reduced, potentially leading to the weakening or death of $H$. rhamnoides ssp. sinensis.

\subsection{Variations in the Mineral Element Contents of $\boldsymbol{H}$. Rhamnoides ssp. Sinensis after Insect Damage}

Insect-damaged plants control the distribution of mineral elements according to the demands of different sections. The potassium content decreases significantly in the branches and cannot be sufficiently translocated to the leaves, which inhibits the synthesis of carbohydrates. A significant decline of zinc content may lead to the suppression of cell division and cell elongation, and a decrease in the manganese content in the top section can affect the rate of photosynthesis of the plants. In the present study, the copper content increased significantly in all sections, which could lead to an increase in the respiration rate and the consumption of nutrients and energy. However, changes in the contents of other elements resulted in the inability to provide the necessary nutrients and energy. The damaged sections could not heal in a short time and the capacity for insect resistance declined; therefore, the plants were susceptible to further damage, which could lead to the weakening or death of plants.

\subsection{Variations in the Total Amino Acid Contents of $H$. Rhamnoides ssp. Sinensis after Insect Damage}

In plants, amino acids are absorbed from the soil or obtained through synthesis and proteolysis. After damage, the total amino acid content increased significantly in the middle and lower sections. Amino acids can promote the absorption and use of mineral elements, thereby inducing dry matter accumulation; its increase in the damaged sections can accelerate wound healing [23].

\subsection{Variations in the Amino Acid Contents of $H$. Rhamnoides ssp. Sinensis after Insect Damage}

Changes in the different types of amino acids in insect-damaged plants resulted in an imbalance in the distribution of amino acids. The proportion of different amino acids therefore differed from that required for the growth of H. hippophaecolus, which may have inhibited its growth.

Increased contents of PRO, CYS, LYS and TRP accelerate the recovery of wounds [24,25], romote insect resistance [26] and improve the capacity to absorb and translocate nitrogen, phosphorus and potassium, which can lead to a better response to insect damage. However, a prolonged increase in the concentration of these amino acids can affect different metabolic pathways, resulting in the inhibition of plant growth and eventually leading to the weakening of plants.

\subsection{Variations in the Protein Contents of H. Rhamnoides ssp. Sinensis after Insect Damage}

Proteins are seldom transported over long distances and they are usually synthesised locally from amino acids [27]. In insect-damaged plants, protein contents declined in the top and lower sections, and increased in the middle section, indicating an increase in the demand and allocation of proteins to damaged sections. The decrease in the total protein content suggested that the rate of proteolysis was higher than that of protein synthesis; the persistence of such imbalance may lead to weakening or death of the plant.

In summary, H. rhamnoides ssp. sinensis plants showed alterations in amino acid, moisture, protein, ash, and mineral element contents in response to damage by $H$. hippophaecolus, and these changes influenced each other. The xylem sustained severe damage and its translocation capacity and its ability to absorb water and minerals were reduced. This may have limited the translocation of nutrients to the damaged sections, leaves and root tips where they were required, which could have inhibited photosynthesis and dry matter accumulation. The activation of plant resistance against the drilling and damage caused by pests for long periods can affect plant metabolism, which could lead to the weakening or death of plants. Further studies addressing the changes of major nutrient substances in the plant after insect damage are required to understand the effects on photosynthesis and metabolism.

\section{Acknowledgements}

The research was supported by Program for New Century Excellent Talents in University (NCET-12-0784).

\section{References}

[1] Y. Lian, X. Chen, "Systematic classification of Hippophae plants," Seabuckthorn, vol. 9, pp. 15-24, March 1996. 
[2] T. S. C. Li, "Product development of sea buckthorn," Trends in new crops and new uses, Alexandria, Egypt: ASHS Press, 2002 .

[3] A. Zeb, "Chemical and nutritional constituents of sea buckthorn juice". Pakistan Journal of Nutrition, vol. 3, pp. 99-106, 2004.

[4] B. Hua, Y. Zhou, D. Fang, S. Chen, "The Cossid Fauna of China (Lepidoptera: Cossidae). Beijing, China: Tianze press, 1990, pp. 56.

[5] R. Tian, M. Tang "Preliminary study on biological characteristics of Holcocerus hippophaecolus," Inner Mongolia forestry science \& technology, vol. 1, pp. 36-38, 1997.

[6] S. Zong, Y. Luo, J. Zhou, S. Liu, "Volatile compounds in healthy and insect damaged Hippophae rhamnoides in natural and planted forests," Z. Naturforschung, vol. 67c, pp. 244-248, 2012.

[7] S. Zong, Z. Wang, Y. Luo, J. Zhang, J. Wen, "Mechanisms underlying host plant selection by Holcocerus hippophaecolus adults," Z. Naturforsch, vol. 66c, pp. 621-626, 2011.

[8] A. Duan, J. Zhang, H. Luo, J. Li, "Phenotypic Diversity of Hybrids Progenies of $H$. rhamnoides subsp. mongolica $\times H$. rhamnoides subsp. Sinensis for Multipurpose Use," The Global Seabuckthorn Research and Development, vol. 13, pp. 006, April 2011.

[9] A. Varshneya, V. Kant, M. Mehta, "Total phenolic contents and free radical scavenging activities of different extracts of seabuckthorn (Hippophae rhamnoides) pomace without seeds," International journal of food sciences and nutrition, vol. 63, pp. 153-159, 2012.

[10] Tifrea, O. Tita, E. Mathe, O. Ketney, "Physicochemical Parameters of Probiotic Yoghurt with Bioactive Natural Products from Sea Buckthorn," Acta Universitatis Cibiniensis Series E: Food Technology, vol. 17, pp. 27-38, June 2013.

[11] Raffo, F. Paoletti, M. Antonelli, "Changes in sugar, organic acid, flavonol and carotenoid composition during ripening of berries of three seabuckthorn (Hippophae rhamnoides L.) cultivars," European Food Research and Technology, vol. 219 , pp. 360-368, August 2004

[12] K. Tiitinen, M. Hakala, H. Kallio, "Quality components of sea buckthorn (Hippophae rhamnoides) varieties," Journal of agricultural and food chemistry, vol. 53, pp. 1692-1699, February 2005.

[13] H. Kallio, B. Yang, P. Peippo, "Effects of different origins and harvesting time on vitamin $\mathrm{C}$, tocopherols, and tocotrienols in sea buckthorn (Hippophae rhamnoides) berries," Journal of Agricultural and Food Chemistry, vol. 50, pp. 6136-6142, September 2002.
[14] GB/T.1931-2009 Determination of the moisture content of wood: Standardization administration of The People's Republic of China.

[15] GB/T.5009.124-2003 Determination of amino acids in foods. Beijing: Standardization administration of The People's Republic of China.

[16] GB/T.5009.5-2003 (The first method) Determination of protein in foods. Beijing: Standardization administration of The People's Republic of China.

[17] GB/T.5009.4-2003 Determination of ash in foods. Beijing: Standardization administration of The People's Republic of China.

[18] GB/T.5009.14-2003 (The first method) Determination of zinc in foods. Beijing: Standardization administration of The People's Republic of China.

[19] GB/T.5009.91-2003 Determination of potassium and sodium in foods. Beijing: Standardization administration of The People's Republic of China.

[20] GB/T.5009.92-2003 (Atomic absorption spectrometry) Determination of calcium in foods. Beijing: Standardization administration of The People's Republic of China.

[21] GB/T.5009.90-2003 Determination of iron, magnesium and manganese in foods. Beijing: Standardization administration of The People's Republic of China.

[22] GB/T.5009.13-2003 (The first method) Determination of copper in foods. Beijing: Standardization administration of The People's Republic of China.

[23] D. Liu, S. Tian, H. Zhao, Z. Gao, "The effect of Amino acid chelated microelement fertilizer on wheat and rice," Chinese Journal of Soil Science, vol. 36, pp. 917-920, 2005.

[24] A. H. A. Khedr, M. A. Abbas, A. A. A. Wahid, W. P. Quick, G. M. Abogadallah, "Proline induces the expression of salt - stress - responsive proteins and may improve the adaptation of Pancratium maritimum L. to salt-stress," Journal of Experimental Botany, vol. 54, pp. 2553-2562, July 2003.

[25] A. Alvarez, M. A. Bermudez, L. C. Romero, C. I. Gotor," Garcia Cysteine homeostasis plays an essential role in plant immunity," New Phytologist, vol. 193, pp. 165-177, January 2012.

[26] G. Szkely, E. Abrah, A. Cseplo, et al. "Duplicated P5CS genes of Arabidopsis play distinct roles in stress regulation and developmental control of proline biosynthesis," The Plant Journal, vol. 53, pp. 11-28, January 2008.

[27] Y. Wang, Z. Shi, Z. Wang, F. Li, "Absorption and utilization of amino acids in plants and its application in agriculture," Soil and Fertilizer Sciences in China, vol. 1, pp. 6-11, 2008. 